\title{
INCIDENCIA DE HIPOTERMIA EN UNIDAD DE RECUPERACIÓN
}

Troncoso Hugot María Ignacia ${ }^{1}$, Sotta Malonnek Esperanza ${ }^{1}$, Torres Pérez David ${ }^{1}$

1 Clínica Santa María.

Introducción: La hipotermia en el perioperatorio es una complicación frecuente y prevenible, pero su monitorización continúa siendo infravalorada. Se asocia a complicaciones como sangrado e infecciones, disconfort y prolonga la estadía en recuperación, aumentando la morbimortalidad, la estadía hospitalaria y los costos. Esto nos llevó a implementar un protocolo de prevención. Objetivo General: Describir la tasa de hipotermia en recuperación, correlacionar con tipo de cirugía realizada y describir tasa de hipotermia los meses posteriores a la introducción de la guía de prevención.

Material y Métodos: Previa aprobación del comité de ética de Clínica Santa María (CSM), se registraron las temperaturas orales en la unidad de recuperación, de todos los pacientes operados entre los meses de marzo y septiembre de 2016. Se definieron tres días al mes para registrar: comienzo, mediados y fin de mes. Se implementó el protocolo de prevención de hipotermia en los pacientes del servicio. Adicionalmente, se registró el tipo de cirugía a la que fue sometido el paciente y la duración del procedimiento. Se les preguntó también por confort térmico en la unidad de recuperación. Consideramos hipotermia con dos puntos de corte: 36 y $35,5^{\circ} \mathrm{C}$. Los datos se presentan como promedio (DS) o porcentaje. Para el análisis de los datos, se utilizó estadística descriptiva y se realizaron comparaciones con $u$ de mann Whitney.

Resultados: Se estudiaron 901 pacientes operados entre marzo y septiembre de 2016. La duración promedio de las cirugías fue de 96 (51) minutos. Del total, $29 \%$ corresponden a cirugías traumatológicas, $26 \%$ a cirugías generales y $14,4 \%$ a cirugías urológicas. La tasa de hipotermia global fue de $52,9 \%$, con umbral de $36^{\circ} \mathrm{C}$ y de $19,8 \%$ con umbral de $35,5^{\circ} \mathrm{C}$. No se encontraron diferencias estadísticamente significativas en las tasas de hipotermia por mes ni por tipo de cirugía.

Conclusiones: Según los resultados, la hipotermia en recuperación es una complicación frecuente, presentada en más del $50 \%$ de los pacientes (umbral $36^{\circ} \mathrm{C}$ ). Se sabe que la medición periférica de temperatura se encuentra subestimada con respecto a la central; por lo que al considerar un segundo umbral de hipotermia $\left(35,5^{\circ} \mathrm{C}\right)$, la tasa de esta disminuyó considerablemente. Además, se preguntó a los pacientes por confort térmico, el cual se correlaciona mejor con el umbral de $35,5^{\circ} \mathrm{C}$ que con el de $36^{\circ} \mathrm{C}$. Ni el tipo de cirugía ni el mes, mostraron variaciones significativas en la prevalencia de hipotermia. Agradecemos a las enfermeras y secretaria de recuperación por el registro de datos.

\section{Referencias}

1. Rev Esp Anestesiol Reanim. 2012;59(7):379389.

2. Rev colomb anestesiol. 2013;41(2):97-103.

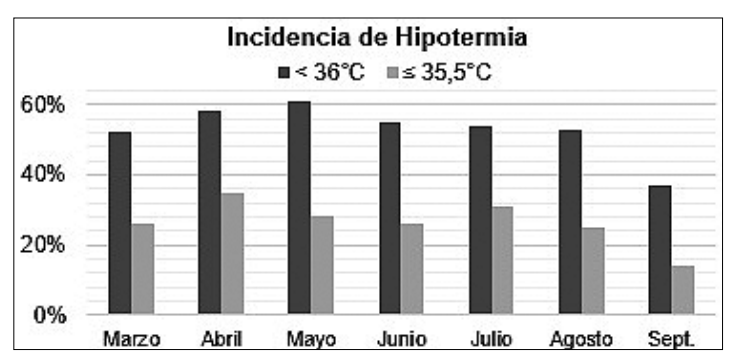

Figura 1. Muestra la incidencia de hipotermia por mes, según umbral. 